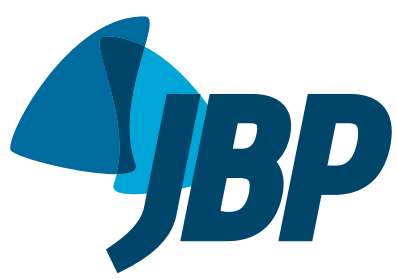

1. Divisão de Pneumologia, Instituto do Coração - InCor - Hospital das Clínicas, Faculdade de Medicina, Universidade de São Paulo, São Paulo (SP) Brasil.

a. (D) http://orcid.org/0000-0002-8025-6940

b. (iD) http://orcid.org/0000-0001-5118-2033

c. (iD http://orcid.org/0000-0003-3297-5948

d. (D) http://orcid.org/0000-0003-3074-445X

e. (D) http://orcid.org/0000-0002-9399-5275

Submitted: 12 June 2017.

Accepted: 16 July 2017

Study carried out in the Divisão de

Pneumologia, Instituto do Coração - InCor

- Hospital das Clínicas, Faculdade de

Medicina, Universidade de São Paulo, São Paulo (SP) Brasil.

\section{The pulmonary microbiome: challenges of a new paradigm}

\author{
André Nathan Costa ${ }^{1, a}$, Felipe Marques da Costa ${ }^{1, b}$, Silvia Vidal Campos ${ }^{1, c}$, \\ Roberta Karla Salles ${ }^{1, d}$, Rodrigo Abensur Athanazio ${ }^{1, e}$
}

\begin{abstract}
The study of the human microbiome-and, more recently, that of the respiratory system-by means of sophisticated molecular biology techniques, has revealed the immense diversity of microbial colonization in humans, in human health, and in various diseases. Apparently, contrary to what has been believed, there can be nonpathogenic colonization of the lungs by microorganisms such as bacteria, fungi, and viruses. Although this physiological lung microbiome presents low colony density, it presents high diversity. However, some pathological conditions lead to a loss of that diversity, with increasing concentrations of some bacterial genera, to the detriment of others. Although we possess qualitative knowledge of the bacteria present in the lungs in different states of health or disease, that knowledge has advanced to an understanding of the interaction of this microbiota with the local and systemic immune systems, through which it modulates the immune response. Given this intrinsic relationship between the microbiota and the lungs, studies have put forth new concepts about the pathophysiological mechanisms of homeostasis in the respiratory system and the potential dysbiosis in some diseases, such as cystic fibrosis, COPD, asthma, and interstitial lung disease. This departure from the paradigm regarding knowledge of the lung microbiota has made it imperative to improve understanding of the role of the microbiome, in order to identify possible therapeutic targets and to develop innovative clinical approaches. Through this new leap of knowledge, the results of preliminary studies could translate to benefits for our patients.
\end{abstract}

Keywords: Microbiota; Microbiology; Immune system.

\section{INTRODUCTION}

"The lungs of healthy humans are sterile sites, unlike the upper airways where there are commensal microorganisms - they live in homeostasis with the human body".(1) Although the respiratory system has a surface area greater than $70 \mathrm{~m}^{2}-$ which is the size of a tennis court-and is in direct contact with the environment, the concept above pervaded knowledge of the respiratory system until the early 21st century, when the first studies based on molecular techniques for the identification of bacterial DNA revealed the presence of genetic material from microorganisms in the lower respiratory tract. ${ }^{(1,2)}$ Much of this delay in knowledge of the lung microbiota is due to the difficulty in characterizing the human lung environment by means of conventional culture techniques based on bacterial growth in material collected by bronchoalveolar lavage. $(2,3)$ This occurs because the bacterial load of the lungs is lower than that of other sites in the human body, such as the gastrointestinal and genitourinary tracts. In addition, there has always been intense debate over possible contamination of material collected from the lower airways with microorganisms from the upper airways, which resulted in exclusion of the lungs from early studies mapping the human microbiome. ${ }^{(2,4-7)}$

After the overcoming of these initial obstacles in the study of the lung microbiome, science has advanced to an understanding of the interaction of this microbiota with the local and systemic immune systems, through which it modulates the immune response in the context of health and of various respiratory diseases. The characterization of the lung microbiome therefore has the potential to provide new concepts about the pathophysiological mechanisms of homeostasis in the respiratory system and the loss of this balance, known as dysbiosis, in some diseases such as cystic fibrosis (CF), COPD, asthma, and interstitial lung diseases. ${ }^{(8-11)}$

It is highly likely that the microbiome and its changes have a direct influence on the natural history of respiratory diseases, as well as there is certainly a change in the microbiota resulting from antibiotic treatment of infectious respiratory tract diseases. In addition, increasing knowledge of the lung microbiome has brought about a discussion of a possible distinction between those bacterial species that are pathogens and those that behave as commensals in the composition of our physiological microbiome. (12-15) $^{-1}$ 
To better tread this new path that opens up to pulmonology, some concepts are important. Microbiota, microbiome, metagenome, and 16S rRNA are terms that pervade studies in this field, and mastery of these terms facilitates the understanding of this new dimension of knowledge (Chart 1 ). With regard to technique, analysis of the bacterial microbiome is based on the identification and sequencing of variable regions of the $16 \mathrm{~S}$ gene encoding bacterial rRNA. Given that this gene is not present in mammals, the confounding bias with human DNA is nonexistant. $(1,4,8)$ Finally, the 16S DNA sequence contains nine variable regions that can be identified by various techniques, the most commonly used being pyrosequencing, phylogenetic microarrays, and terminal restriction fragment length

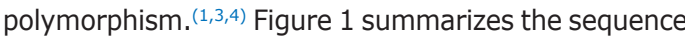
of events leading to the recognition of the microbiome at a given site.

Although the results of published studies differ a little, Proteobacteria, Firmicutes, and Bacteroidetes are the most commonly identified bacterial phyla in healthy individuals. With regard to genus, Streptococcus, Prevotella, Fusobacteria, and Veillonella predominate, with potential pathogens, such as Haemophilus and Neisseria, contributing a small fraction. However, those studies are based on case series involving a small number of healthy subjects and few centers around the world. $(2,3,16)$

Being as important as qualitative knowledge of the bacteria present in the lungs, describing the richness of organisms and the coexistence of various species is essential. Although the healthy lung microbiome presents low colony density, it presents high diversity; however, some pathological conditions lead to a loss of that diversity, with increasing concentrations of some bacterial genera, to the detriment of others. ${ }^{(15,17,18)}$ This could imply the development of specific therapies, to the detriment of broad-spectrum antibiotic therapies, with great potential to cause more imbalance in an already dysbiotic microbiome. ${ }^{(19)}$ Following this line of reasoning, the anti-inflammatory effects of macrolides, which are considered to be immunomodulators and are used for prolonged periods in diseases such as bronchiectasis, bronchiolitis obliterans, and COPD, have been revisited, since these anti-inflammatory properties appear to be related to changes in the lung microbiota and in the microbial metabolites, with subsequent downregulation of alveolar macrophage function. ${ }^{(13)}$

Finally, as far as the microbial population in the respiratory system is concerned, early studies failed to address two important components of the lung ecosystem: viruses and fungi. The lung mycobiome and virome, especially in some conditions, such as CF and lung transplantation, appear to have particular importance. (20) Viral and fungal identification uses the same technique as that used in bacterial microbiota analysis, but with detection of $18 \mathrm{~S}$ rRNA in the case

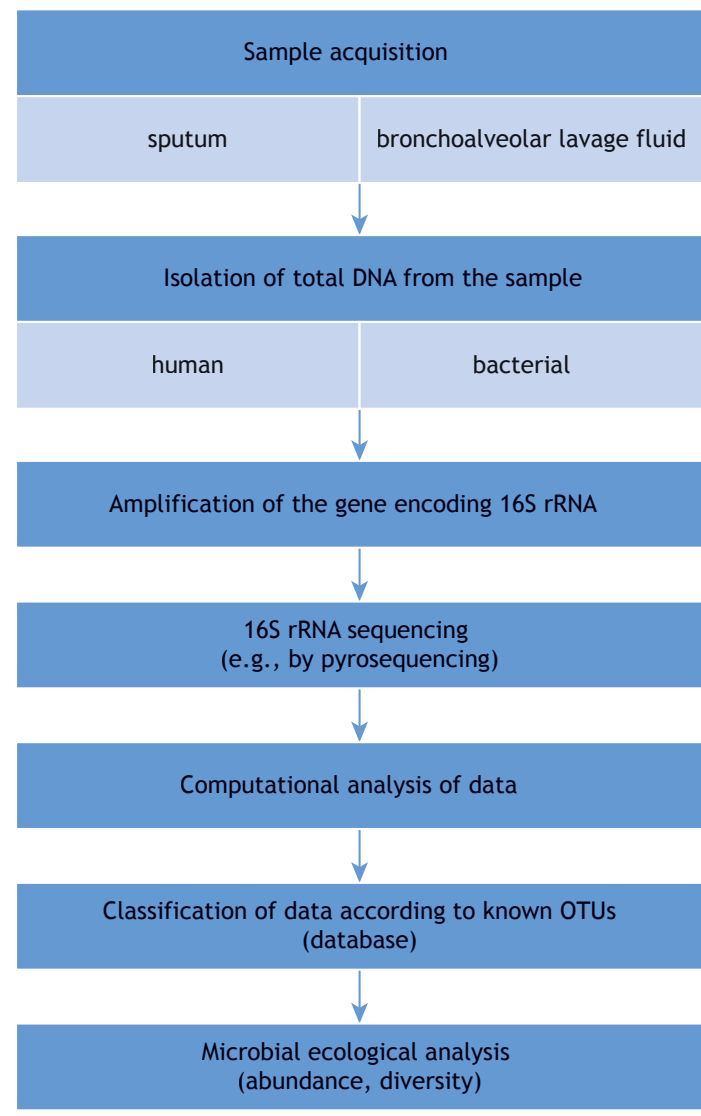

Figure 1. Sequence of events leading to the recognition of the microbiome at a given site. OTU: operational taxonomic unit.

Chart 1. Glossary of nomenclature and definitions used in the routine evaluation of the human microbiome.

\begin{tabular}{|c|c|}
\hline Microbiota & All of the microorganisms of a given region or habitat \\
\hline Microbiome & The collection of microorganisms, their genes, and their environmental interactions \\
\hline Metagenome & $\begin{array}{l}\text { Genetic information of the microbiota, obtained from genetic sequencing that is } \\
\text { analyzed, organized, and identified through computational tools, using databases of } \\
\text { previously known sequences }\end{array}$ \\
\hline 16S rRNA & $\begin{array}{l}\text { Component of the prokaryotic } 30 \text { S subunit. It encodes DNA } 165 \text { genes, used to obtain } \\
\text { phylogenetic data }\end{array}$ \\
\hline Operational taxonomic unit & $\begin{array}{l}\text { Operational definition of a species or group of species, used when only DNA sequence } \\
\text { data are available }\end{array}$ \\
\hline Dysbiosis & $\begin{array}{l}\text { An imbalance in the composition of the microbiota of a given niche, related to changes } \\
\text { in local conditions }\end{array}$ \\
\hline
\end{tabular}


of fungi and with nucleic acid sequencing and PCR in the case of viruses. ${ }^{(21)}$

\section{THE LUNG MICROBIOME AND ITS RELATIONSHIP WITH THE GASTROINTESTINAL TRACT}

The theory that the facial sinuses were the major determinants of the microbiological changes found in the lower respiratory tract persisted for a long time. The glottis was then considered to be an effective structure in protecting the lungs from the gastrointestinal tract. However, the microbiome of the lower respiratory tract is now recognized to be similar to that of the oropharynx, leading to the concept that microbial migration from this region is the major determinant of the lung microbiome in healthy individuals. ${ }^{(22)}$ Microaspiration appears to play a key role in shaping the lung microbiome, although other bacteria that are present in the lower respiratory tract, such as those of the genera Prevotella, Veillonella, and Streptococcus, have their origin attributable to inhalation through the upper airways. $(23,24)$ The interrelationship of these systems and the local determinants of the lung microbiome are presented in Figures 2 and 3.

\section{THE MICROBIOTA AND IMMUNE MODULATION}

Commensal interactions between microorganisms and humans throughout evolution, as well as the relevance of the luminal ecosystem (genitourinary and gastrointestinal tracts) in immune modulation, have emerged as a new paradigm. This ecosystem is separated from the interior of the host by a thin layer of epithelial cells that acts as an interface between the host and the environment, and this epithelium is equipped with cilia, microvilli, mucus-producing cells, and intercellular junctions that allow physiological functions while in contact with the microbiota. ${ }^{(25)}$ Studies of sterile (germ-free) mice have shown that resident bacteria directly influence epithelial metabolism, proliferation, turnover, and barrier function. ${ }^{(25)}$ In the respiratory system, members of the microbiota, in association with environmental non-viable particulate antigens, are continuously presented to the mucosa and processed by dendritic cells and macrophages, with subsequent formation of memory or activation of $T$ and $B$ effector cells. ${ }^{(25)}$ In addition, studies of the gastrointestinal tract have demonstrated the ability of the immune system to discriminate between pathogenic and commensal bacteria, through toll-like receptors present in T lymphocytes, in a process that would allow symbiotic colonization, that is, a kind of "peace agreement" between the resident microbiota and the respiratory mucosa, ${ }^{(25,26)}$ as exemplified in Figure 4.

Evidence, however, shows that abnormal regulation of this host-microbiota relationship plays an important role in the pathophysiology of several lung inflammatory disorders. Therefore, characterizing the composition of the airway microbiota as a prognostic marker or as a guide to drug therapy is of interest in several chronic lung diseases, ${ }^{(27)}$ as described below.

\section{THE MICROBIOTA IN VARIOUS LUNG DISEASES}

\section{Asthma}

Asthma is a complex, heterogeneous disease associated with allergic phenomena that has increased in prevalence in recent decades. The hygiene hypothesis is one of the major theories explaining this finding. (28) Low-level exposure to bacterial infections during childhood may be responsible for modulation of the immune response with strong emphasis on the Th2-allergic pathway. Therefore, there has been increasing interest in the role of both the lung and gastrointestinal microbiome. An experimental study of bacteria-free mice demonstrated that those animals showed an exaggerated Th2 response when stimulated with ovalbumin, developing increased eosinophilia in the airways, hyperresponsiveness, and mucus hypersecretion. When those animals were placed to grow alongside mice with the usual bacterial microbiota, both groups showed the same Th2 response intensity, which indicates that the usual microbiome functions as a protective factor against allergic diseases. ${ }^{(29)}$

Given that bacterial colonization of mucous membranes is related to the development and orchestration of the immune response of healthy individuals, changes in this interrelationship in early stages of life may contribute to the development of allergic diseases in adulthood. ${ }^{(30)}$ In a study comparing two agricultural communities with similar habits, but with a distinct prevalence of asthma and allergic sensitization, the presence of a microbial composition with increased endotoxin production was related to a lower prevalence of allergic disorders. ${ }^{(31)}$ In addition, a nasal microbiota with decreased diversity of species, especially when accompanied by the presence of Moraxella spp., has also been associated with a higher prevalence of asthma. ${ }^{(32)}$

Among adults, patients with asthma have been shown to have a higher prevalence of organisms of the phylum Proteobacteria, such as Haemophilus influenzae, compared with healthy controls. ${ }^{(33,34)}$ Studies in this area are scarce and involve a small number of patients, leading to heterogeneity of findings. Nevertheless, all indicate the presence of lung-microbiota-related dysbiosis in asthma patients, which can be influenced both by disease severity and by inhaled or systemic corticosteroid use. ${ }^{(35,36)}$

\section{COPD}

Studies comparing the microbiome of smokers, former smokers, and healthy individuals are scarce and report some conflicting results regarding the long-term effects of tobacco exposure. ${ }^{(37,38)}$ Nevertheless, there are indications that dysbiosis occurs in smokers, with an increase in the prevalence of the phylum Firmicutes and of Neisseria spp., associated with a relative 


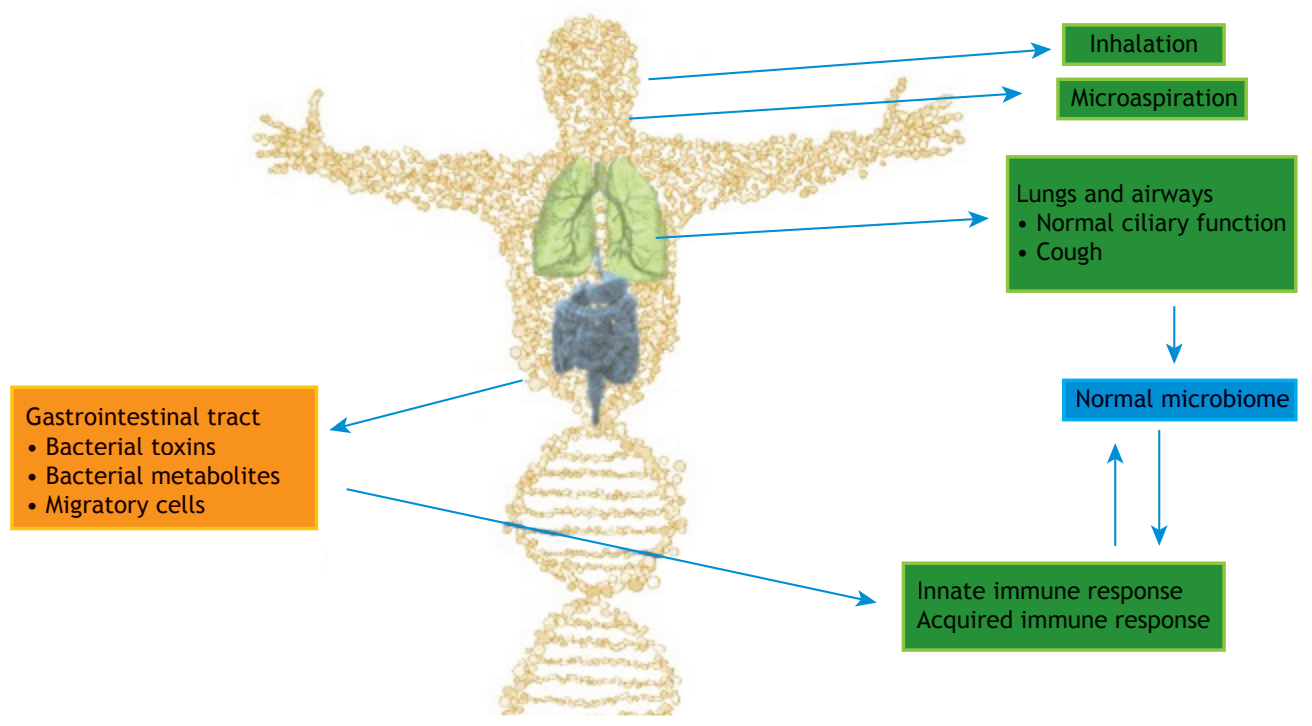

Figure 2. Determinants of the lung microbiome and the intestine-lung axis. The composition of the human microbiota is determined by the association of environmental factors, the host immune response, and genetic characteristics. The intestine microbiota, which is incomparably greater in size than the lung microbiota, can influence the lower respiratory tract both directly, through microaspiration, and indirectly, through modulation of the immune response as a result of the production of bacterial metabolites and their interaction with the host inflammatory cells. Inhalation of external agents is also a pathway to lung colonization and will depend, as will intestinal tract colonization, on local factors, such as oxygen tension, tissue $\mathrm{pH}$, blood perfusion, nutrient concentration, proper mucociliary transport, and disruption of the lung architecture.
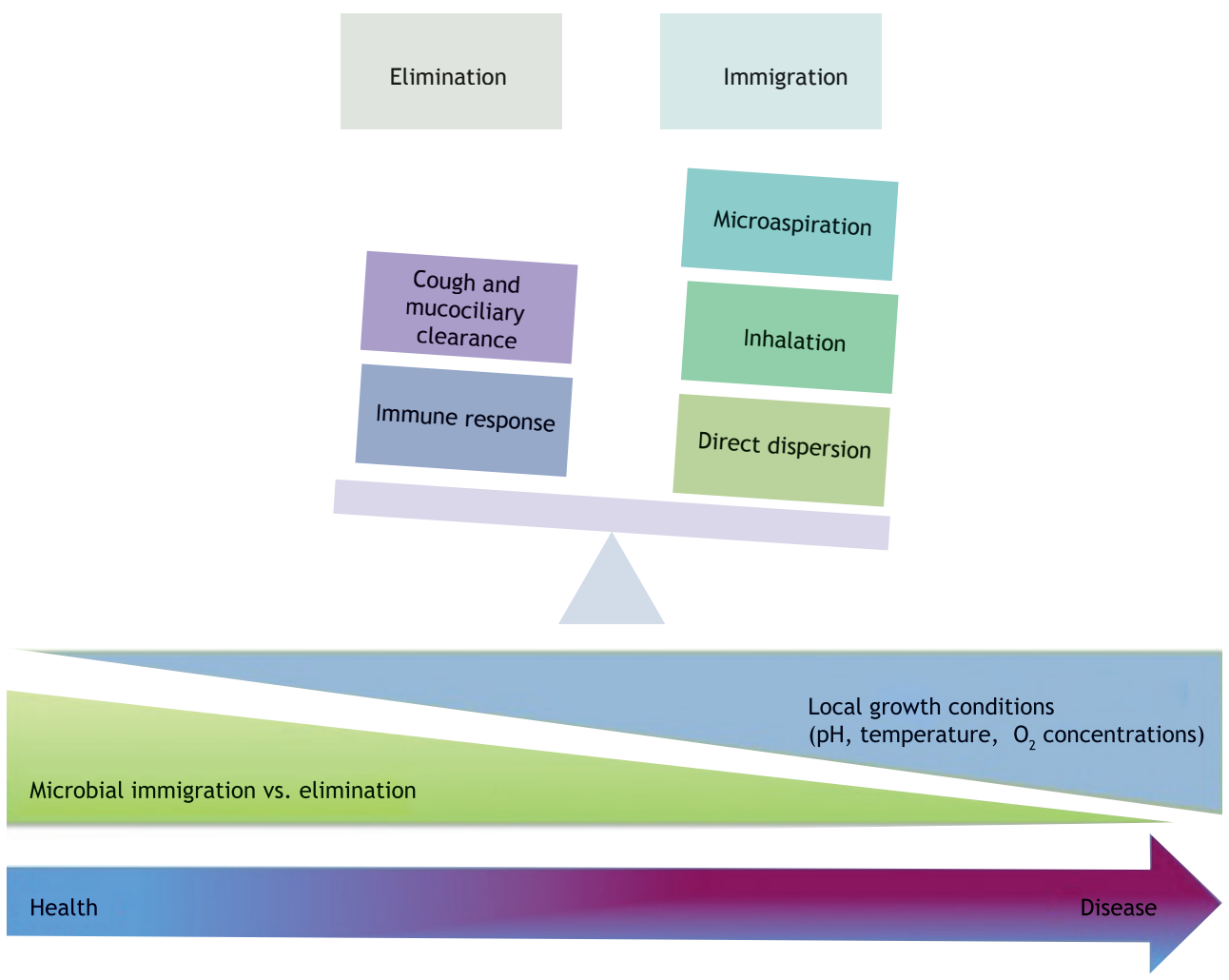

Figure 3. Determinants of the microbiome of the respiratory system: microbial immigration, elimination, and proliferation. In healthy individuals, the microbiome is determined primarily by immigration and elimination. In severe lung disease, local growth conditions are determinants of the composition of the microbiome. 


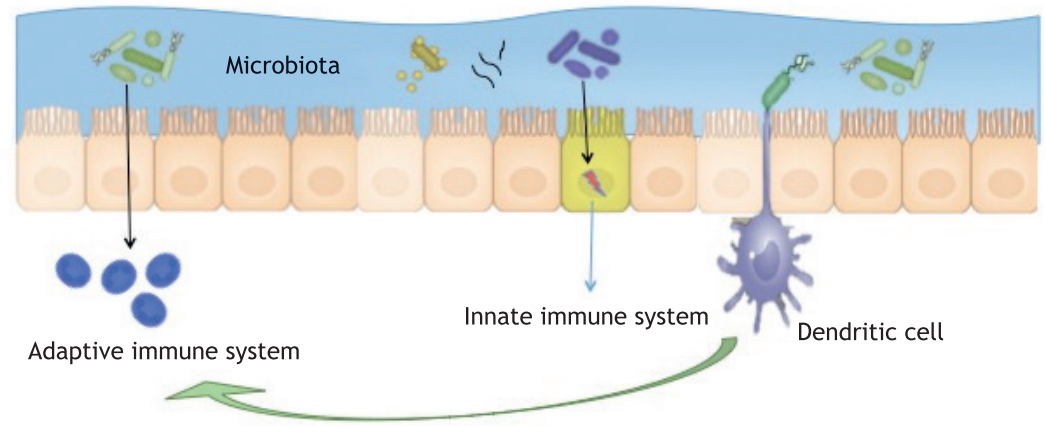

Figure 4. Microbiota interface and interaction with local immunity. Members of the microbiota, in association with environmental non-viable particulate antigens, are continuously sampled by the mucosa and processed by dendritic cells and macrophages, with subsequent formation of memory or activation of $\mathrm{T}$ and $\mathrm{B}$ effector cells. Therefore, various commensal microorganisms influence the innate immunity and the adaptive immunity.

decrease in the abundance of Proteobacteria. ${ }^{(37)}$ In contrast, several studies of patients with COPD have revealed that their lung microbiome is clearly different from that of healthy controls. ${ }^{(39-42)}$ In addition, among patients with COPD, depending on the site from which the material is collected, differences are also found in the composition of the microbiome, such as when, for instance, sputum and bronchoalveolar lavage fluid are compared. ${ }^{(42)}$

With regard to COPD exacerbations, numerous studies have also demonstrated that there is a relative increase in the abundance of a given genus, to the detriment of others. ${ }^{(43-45)}$ This change is related to a proinflammatory state and can be triggered, among other causes, by viral infections ${ }^{(43)}$ and by bacterial-fungal interactions in the airway. ${ }^{(46)}$ These findings further question the role of antibiotics in COPD exacerbation, given that antibiotics can play a deleterious role in the lung microbiome because they reduce bacterial abundance. However, systemic corticosteroid use does not significantly change microbiological diversity and, in parallel, can increase the abundance of certain genera that are considered as normal flora. ${ }^{(44)}$

\section{Bronchiectasis and CF}

Airway colonization in suppurative lung diseases-CF and non-CF bronchiectasis-plays a key role in the progression of their clinical and radiological manifestations, and understanding the role of the microbiota is key to understanding the pathophysiology of these manifestations. While traditional culturebased knowledge shows the importance of wellknown pathogens, such as Haemophilus influenzae, Pseudomonas aeruginosa, and Moraxella catarrhalis in non-CF bronchiectasis, as well as Staphylococcus aureus and Burkholderia cepacia complex in CF, molecular studies have shown that previously unrecognized organisms are abundantly present in some patients with suppurative disease. ${ }^{(27)}$ Examples of this colonization include the presence of Stenotrophomonas maltophilia and Achromobacter spp., as well as reports of Mycobacterium abscessus and Aspergillus fumigatus. ${ }^{(10)}$
Studies of the microbiome in patients with CF have demonstrated that samples from younger, healthier patients usually exhibit bacterial communities that are more diverse, whereas lung explants from patients with end-stage lung disease show extremely low diversity, with only one or two detectable pathogenic bacteria, such as $P$. aeruginosa and $S$. maltophilia. ${ }^{(47)}$ This microbiological change, during the lifetime of a

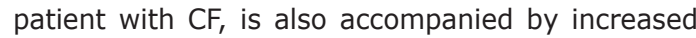
abundance and greater phylogenetic similarity among the colonies of each species. ${ }^{(48,49)}$

In non-CF bronchiectasis, the simultaneous competition for survival between pathogenic and commensal bacteria elicits an innate immune response from the host, with polarization of T-cell subtype response, activating or perpetuating the inflammatory process in the terminal airways, similarly to what occurs in chronic inflammatory bowel diseases, such as ulcerative colitis. In the context of inflammatory bowel diseases, it is of note that there is an association between the development of bronchiectasis and colectomy for advanced ulcerative colitis, raising the possibility that the intestinal microbiota influences the lung microbiota through systemic immunoregulation after excluding in intestinal barrier. ${ }^{(12)}$

Finally, in suppurative diseases, an understanding of the pathogenic and commensal microbiota is crucial for differentiating between infection and colonization, that is, balance/health vs. dysbiosis/disease. It should also be borne in mind that, for this group of patients, the study of the fungal and viral microbiome (microbiome and virome) is essential, and there have been few studies addressing these issues to date. The literature still lacks controlled clinical trials; most studies are descriptive studies or reviews.

\section{Pulmonary tuberculosis}

The microbiome in the context of tuberculosis remains a poorly studied area, despite the high global burden of tuberculosis. ${ }^{(50)}$ Many existing studies have focused on the microbiota outside the respiratory system, 
including reports of an increased presence of Candida spp. and a loss of diversity in the intestinal microbiota as a result of tuberculosis treatment. ${ }^{(51,52)}$ In addition, there is little agreement between those studies and analyses of the lung microbiome in tuberculosis. Cui et al. ${ }^{(53)}$ reported that healthy lungs and those infected with Mycobacterium tuberculosis had many microorganisms in common, including those of the phyla Bacteroidetes, Proteobacteria, and Actinobacteria, with a predominance of Firmicutes and Bacteroidetes. In contrast, Wu et al. ${ }^{(54)}$ found a very different list of microorganisms associated with tuberculosis, including those of the genera Streptococcus, Granulicatella, and Pseudomonas. An interesting aspect of that study is the comparison among the microbiota of patients with newly diagnosed tuberculosis, that of recurrence cases, and that of treatment failure cases. The Pseudomonas-to-Mycobacterium ratio was higher in recurrence cases than in newly diagnosed cases, whereas the Treponema-to-Mycobacterium ratio was lower in recurrence cases than in newly diagnosed cases, indicating that disruption of these bacteria may be a risk factor for recurrence of tuberculosis. ${ }^{(54)}$ These data suggest that the presence of certain bacteria and lung dysbiosis may be associated not only with the development of tuberculosis but also with recurrence of tuberculosis and treatment failure, indicating a possible role of the microbiota in the pathogenesis of tuberculosis and in tuberculosis treatment outcomes.

\section{INTERSTITIAL LUNG DISEASES}

In 2008, Varney et al. ${ }^{(55)}$ published a clinical trial evaluating the use of trimethoprim-sulfamethoxazole in patients with idiopathic pulmonary fibrosis (IPF). They demonstrated that the group receiving the antibiotic therapy showed clinical and functional improvement, ${ }^{(55)}$ and hypothesized a potential effect on the lung microbiota. More recently, data from a cohort study assessing 55 patients with IPF demonstrated that there is a relationship between the predominance of specific bacteria of the genera Staphylococcus and Streptococcus and interstitial lung disease exacerbation. ${ }^{(56)}$ Also in 2014, Molyneaux et al. (57) observed that bronchoalveolar lavage fluid from patients with IPF exhibited an increased quantity of bacteria compared with that from healthy controls, as well as observing differences in the composition and diversity of this microbiota, and linked this dysbiosis to parenchymal disease progression. Later, genetic analyses of patients with IPF showed increase and maintenance in the expression of genes related to the host immune response, which acts as a continuous stimulus damaging to the alveolar epithelium, as well as being related to local fibroblast activation, ${ }^{(58,59)}$ subsequently suggesting a relationship between the microbiome and fibrosis progression. Attempts at reversal of dysbiosis and, ultimately, the cessation of tissue damage have been extensively investigated in the context of interstitial fibrosing diseases; however, it is too early to say that the microbiota is directly related to disease progression. ${ }^{(27)}$

\section{OTHER CLINICAL SETTINGS IN PULMONOLOGY}

After initial advances in the understanding of the microbiome of the respiratory system in the context of the most prevalent diseases, it is expected that this understanding will revolutionize the concepts of pathogenesis in several clinical settings. In the context of mechanical ventilation and ventilator-associated pneumonia (VAP), that is not different. A recent study of 35 patients suggested that mechanical ventilation per se is more strongly associated with a change in the lung microbiota than is the use of systemic antibiotics, and that respiratory tract dysbiosis is more intense in patients who developed VAP than in those who did not. ${ }^{(60)}$ Still in the context of VAP, microbiome analysis may also aid in etiologic diagnosis and in differentiating between pneumonia and colonization with a potential pathogen. ${ }^{(61)}$

Lung transplantation is another area that is in a state of flux. The respiratory system of transplant recipients is a point of special interest, given the wide use of prophylactic antibiotics and immunosuppressive drugs in this population. The microbiota of the transplanted lung appears to be different from that of healthy lungs, mainly because of the presence of the family Burkholderiaceae. ${ }^{(62)}$ In addition, the change in the microbiota appears to influence the development of chronic graft dysfunction. (63) A study of 203 bronchoalveolar lavage fluid samples from 112 transplant recipients revealed that some bacteria played a pro-inflammatory role (genera Staphylococcus and Pseudomonas) and some played a role of lower stimulation of the immune system (genera Prevotella and Streptococcus). ${ }^{(64)}$ A dysbiosis in those individuals appears to be associated with various profiles of inflammation and elaboration by lung macrophages, contributing to the genesis of chronic dysfunction. This interaction between bacterial communities and innate immune response offers new intervention pathways to preventing chronic graft dysfunction.

Clinical oncology has also advanced in the understanding of the correlations between microorganisms and lung neoplasms. After the identification of molecular markers, such as EGFR, programmed cell death protein-1, and anaplastic lymphoma kinase, which have customized the therapeutic approach, it is now the microbiome that presents itself as a possible marker of disease activity and perhaps a therapeutic target. Some microorganisms have shown a direct relationship with neoplasms in other organs, such as Helicobacter pylori in stomach cancer and HPV in uterine cervical cancer. Periodontal disease can be associated with lung cancer, suggesting an association between the oral microbiome and the risk of lung carcinoma. ${ }^{(65)}$ Corroborating these hypotheses, Vogtmann et al. reported that cases of lung cancer among nonsmoking females showed a 
decreased relative abundance of organisms of the phyla Spirochaetes and Bacteroidetes and an increased relative abundance of those of the phylum Firmicutes in analyses of the oral microbiota. ${ }^{(66)}$ Finally, a study comparing bronchoalveolar lavage fluid from patients with neoplasms with that from patients with benign tumors found the genera Veillonella and Megasphaera to be predictors of lung cancer, suggesting an association between an altered lung microbiota and the presence of neoplasm. ${ }^{(67)}$

\section{SKEPTICISM IN THE ANALYSIS}

Albeit exciting, the study of the microbiome should be viewed with some caution, and it has been said that its greatest risk is that of drowning in its own tsunami of information. (68) There is a risk of a series of speculative associations being made between the microbiota and states of health and disease, and of these connections being shown to be spurious or much more complex than shown by early evaluations.

Would the microbial communities be altered in the lungs because of respiratory diseases or are the lungs diseased because of the dysbiosis of these microorganisms? The immune system and the microbiome are so closely intertwined that this differentiation is extremely difficult. Most studies on this subject have been descriptive and, despite being replete with provocative correlations, have failed to elucidate causality between modulation of respiratory tract diseases and the resident microbiota, and to determine what temporally comes first: dysbiosis or lung disease. ${ }^{(69)}$ These are some of the issues that are pressing when it comes to designing new studies.

\section{FINAL CONSIDERATIONS}

We are entering a new era in the understanding of lung diseases from the standpoint of the interaction of bacterial communities and metabolites with the immunological and functional mechanisms of various respiratory tract diseases. In this context, given the departure from the paradigm regarding knowledge of the lung microbiota, it is imperative to improve understanding of the interaction between the microbiota and the host so that we can advance our understanding of the pathophysiological processes of respiratory diseases, as well as identifying possible therapeutic targets and developing innovative clinical approaches. The translation of this information into better patient care will undoubtedly be the greatest challenge in the study of the microbiome and its potentialities.

\section{REFERENCES}

1. Beck JM. ABCs of the lung microbiome. Ann Am Thorac Soc. 2014;11 Suppl 1:S3-6. https://doi.org/10.1513/AnnalsATS.201306$188 \mathrm{MG}$

2. Marsland BJ, Gollwitzer ES. Host-microorganism interactions in lung diseases. Nat Rev Immunol. 2014;14(12):827-35. https://doi org/10.1038/nri3769

3. Rogers GB, Shaw D, Marsh RL, Carroll MP, Serisier DJ, Bruce KD Respiratory microbiota: addressing clinical questions, informing clinical practice. Thorax. 2015;70(1):74-81. https://doi.org/10.1136/ thoraxjnl-2014-205826

4. Human Microbiome Project Consortium. Structure, function and diversity of the healthy human microbiome. Nature 2012;486(7402):207-14. https://doi.org/10.1038/nature11234

5. Li K, Bihan M, Yooseph S, Methé BA. Analyses of the microbia diversity across the human microbiome. PLoS One. 2012;7(6) e32118. https://doi.org/10.1371/journal.pone.0032118

6. Huang YJ, Charlson ES, Collman RG, Colombini-Hatch S, Martinez FD, Senior RM. The role of the lung microbiome in health and disease: A national Heart, Lung, and Blood Institute workshop report. Am J Respir Crit Care Med. 2013;187(12):1382-7. https://doi. org/10.1164/rccm.201303-0488WS

7. Gensollen T, lyer SS, Kasper DL, Blumberg RS. How colonization by microbiota in early life shapes the immune system. Science. 2016;352(6285):539-44. https://doi.org/10.1126/science.aad9378

8. Jiao X, Zheng X, Ma L, Kutty G, Gogineni E, Sun Q, et al. A Benchmark Study on Error Assessment and Quality Control of CCS Reads Derived from the PacBio RS. J Data Mining Genomics Proteomics. 2013:4(3). pii: 16008. https://doi.org/10.4172/2153-0602.1000136

9. Mammen MJ, Sethi S. COPD and the microbiome. Respirology 2016;21(4):590-9. https://doi.org/10.1111/resp.12732

10. Surette MG. The cystic fibrosis lung microbiome. Ann Am Thorac Soc. 2014;11 Suppl 1:S61-5. https://doi.org/10.1513/AnnalsATS.201306$159 \mathrm{MG}$

11. Han MK, Zhou Y, Murray S, Tayob N, Lama VN, Moore BB, et al. Lung microbiome and disease progression in idiopathic pulmonary fibrosis: an analysis of the COMET study. Lancet Respir Med. 2014;2(7):54856 https://doi.org/10.1016/S2213-2600(14)70069-4

12. Boyton RJ, Reynolds CJ, Quigley KJ, Altmann DM. Immune mechanisms and the impact of the disrupted lung microbiome in chronic bacterial lung infection and bronchiectasis. Clin Exp Immunol. 2013;171(2):117-23. https://doi.org/10.1111/cei.12003

13. Segal LN, Clemente JC, Wu BG, Wikoff WR, Gao Z, Li Y, et al. Randomised, double-blind, placebo-controlled trial with azithromycin selects for anti-inflammatory microbial metabolites in the emphysematous lung. Thorax. 2017;72(1):13-22. https://doi. org/10.1136/thoraxjnl-2016-208599

14. Sze MA, Dimitriu PA, Suzuki M, McDonough JE, Campbell JD, Brothers JF, et al. Host response to the lung microbiome in chronic obstructive pulmonary disease. Am J Respir Crit Care Med. 2015;192(4):438-45. https://doi.org/10.1164/rccm.201502-02230C

15. Wang Z, Bafadhel M, Haldar K, Spivak A, Mayhew D, Miller BE, et al. Lung microbiome dynamics in COPD exacerbations. Eur Respir J 2016;47(4):1082-92. https://doi.org/10.1183/13993003.01406-2015

16. Chotirmall SH, Gellatly SL, Budden KF, Mac Aogain M, Shukla SD, Wood DL, et al. Microbiomes in respiratory health and disease: An Asia-Pacific perspective. Respirology. 2017;22(2):240-250. https:// doi.org/10.1111/resp.12971

17. Scales DC. The Implications of a Tracheostomy for Discharge Destination. Am J Respir Crit Care Med. 2015;192(4):404-5. https:// doi.org/10.1164/rccm.201505-1007ED

18. von Mutius E. Environmental microorganisms and lung health. Ann Am Thorac Soc. 2014;11 Suppl 1:S13-5. https://doi.org/10.1513/ AnnalsATS.201306-155MG

19. Blaser MJ. Antibiotic use and its consequences for the norma microbiome. Science. 2016;352(6285):544-5. https://doi.org/10.1126/ science.aad9358

20. Underhill DM, lliev ID. The mycobiota: interactions between commensal fungi and the host immune system. Nat Rev Immunol. 2014;14(6):405-16. https://doi.org/10.1038/nri3684

21. Mitchell AB, Oliver BG, Glanville AR. Translational Aspects of the Human Respiratory Virome. Am J Respir Crit Care Med. 2016;194(12):1458-1464. https://doi.org/10.1164/rccm.201606$1278 \mathrm{Cl}$

22. Bassis CM, Erb-Downward JR, Dickson RP, Freeman CM, Schmidt TM, Young VB, et al. Analysis of the upper respiratory tract microbiotas as the source of the lung and gastric microbiotas in healthy individuals. MBio. 2015;6(2):e00037. https://doi.org/10.1128/ mBio.00037-15 
23. Venkataraman $A$, Bassis CM, Beck JM, Young VB, Curtis JL, Huffnagle GB, et al. Application of a neutral community model to assess structuring of the human lung microbiome. MBio. 2015;6(1). pii: e02284-14. https://doi.org/10.1128/mBio.02284-14

24. Dickson RP, Erb-Downward JR, Huffnagle GB. Homeostasis and its Disruption in the Lung Microbiome. Am J Physiol Lung Cell Mol Physiol. 2015;309(10):L1047-55. https://doi.org/10.1152/ ajplung.00279.2015

25. Neish AS. Mucosal immunity and the microbiome. Ann Am Thorac Soc. 2014;11 Suppl 1:S28-32. https://doi.org/10.1513/ AnnalsATS.201306-161MG

26. Round JL, Lee SM, Li J, Tran G, Jabri B, Chatila TA, et al. The Tolllike receptor 2 pathway establishes colonization by a commensal of the human microbiota. Science. 2011;332(6032):974-7. https://doi. org/10.1126/science.1206095

27. Faner R, Sibila O, Agustí A, Bernasconi E, Chalmers JD, Huffnagle $\mathrm{GB}$, et al. The microbiome in respiratory medicine: current challenges and future perspectives. Eur Respir J. 2017:49(4). pii: 1602086 https://doi.org/10.1183/13993003.02086-2016

28. Strachan DP. Hay fever, hygiene, and household size. BMJ. 1989;299(6710):1259-60. https://doi.org/10.1136/ bmj.299.6710.1259

29. Herbst T, Sichelstiel A, Schär C, Yadava K, Bürki K, Cahenzli J, et al. Dysregulation of allergic airway inflammation in the absence of microbial colonization. Am J Respir Crit Care Med. 2011;184(2):198205. https://doi.org/10.1164/rccm.201010-15740C

30. Gensollen T, Iyer SS, Kasper DL, Blumberg RS. How colonization by microbiota in early life shapes the immune system. Science. 2016;352(6285):539-44. https://doi.org/10.1126/science.aad9378

31. Stein MM, Hrusch CL, Gozdz J, Igartua C, Pivniouk V, Murray SE, et al. Innate Immunity and Asthma Risk in Amish and Hutterite Farm Children. N Engl J Med. 2016;375(5):411-421. https://doi. org/10.1056/NEJMoa1508749

32. Depner M, Ege MJ, Cox MJ, Dwyer S, Walker AW, Birzele LT, et al. Bacterial microbiota of the upper respiratory tract and childhood asthma. J Allergy Clin Immunol. 2017;139(3):826-834.e13. https:// doi.org/10.1016/i.jaci.2016.05.050

33. Hilty M, Burke C, Pedro H, Cardenas P, Bush A, Bossley C, et al. Disordered microbial communities in asthmatic airways. PLOS One. 2010;5(1):e8578. https://doi.org/10.1371/journal.pone.0008578

34. Huang YJ, Nelson CE, Brodie EL, Desantis TZ, Baek MS, Liu J, et al. Airway microbiota and bronchial hyperresponsiveness in patients with suboptimally controlled asthma. J Allergy Clin Immunol. 2011;127(2):372-381.e1-3

35. Denner DR, Sangwan N, Becker JB, Hogarth DK, Oldham J, Castillo $\mathrm{J}$, et al. Corticosteroid therapy and airflow obstruction influence the bronchial microbiome, which is distinct from that of bronchoalveolar lavage in asthmatic airways. J Allergy Clin Immunol. 2016;137(5):1398-1405.e3. https://doi.org/10.1016/j. jaci.2015.10.017

36. Durack J, Lynch SV, Nariya S, Bhakta NR, Beigelman A, Castro M, et al. Features of the bronchial bacterial microbiome associated with atopy, asthma, and responsiveness to inhaled corticosteroid treatment. J Allergy Clin Immunol. 2017;140(1):63-75. https://doi. org/10.1016/j.jaci.2016.08.055

37. Morris A, Beck JM, Schloss PD, Campbell TB, Crothers K, Curtis JL, et al. Comparison of the respiratory microbiome in healthy nonsmokers and smokers. Am J Respir Crit Care Med. 2013:187(10):1067-75. https://doi.org/10.1164/rccm.201210-19130C

38. Munck C, Helby J, Westergaard CG, Porsbjerg C, Backer V, Hansen LH. Smoking Cessation and the Microbiome in Induced Sputum Samples from Cigarette Smoking Asthma Patients. PLoS One. 2016;11(7):e0158622. https://doi.org/10.1371/journal.pone.0158622

39. Sze MA, Dimitriu PA, Hayashi S, Elliott WM, McDonough JE, Gosselink JV, et al. The lung tissue microbiome in chronic obstructive pulmonary disease. Am J Respir Crit Care Med. 2012;185(10):107380. https://doi.org/10.1164/rccm.201111-20750C

40. Pragman AA, Kim HB, Reilly CS, Wendt $C$, Isaacson RE. The lung microbiome in moderate and severe chronic obstructive pulmonary disease. PLoS One. 2012;7(10):e47305. https://doi.org/10.1371/ journal.pone.0047305

41. Millares $L$, Ferrari $R$, Gallego $M$, Garcia-Nuñez $M$, Pérez-Brocal $V$, Espasa $M$, et al. Bronchial microbiome of severe COPD patients colonised by Pseudomonas aeruginosa. Eur J Clin Microbiol Infect Dis. 2014;33(7):1101-11. https://doi.org/10.1007/s10096-013-2044-0

42. Cabrera-Rubio R, Garcia-Núñez M, Setó L, Antó JM, Moya A, Monsó
E, et al. Microbiome diversity in the bronchial tracts of patients with chronic obstructive pulmonary disease. J Clin Microbiol. 2012;50(11):3562-8. https://doi.org/10.1128/JCM.00767-12

43. Molyneaux PL, Mallia P, Cox MJ, Footitt J, Willis-Owen SA, Homola $D$, et al. Outgrowth of the bacterial airway microbiome after rhinovirus exacerbation of chronic obstructive pulmonary disease Am J Respir Crit Care Med. 2013;188(10):1224-31. https://doi. org/10.1164/rccm.201302-03410C

44. Dy R, Sethi S. The lung microbiome and exacerbations of COPD. Curr Opin Pulm Med. 2016;22(3):196-202. https://doi.org/10.1097/ MCP. 0000000000000268

45. Huang YJ, Sethi S, Murphy T, Nariya S, Boushey HA, Lynch SV. Airway microbiome dynamics in exacerbations of chronic obstructive pulmonary disease. J Clin Microbiol. 2014;52(8):2813-23. https://doi. org/10.1128/JCM.00035-14

46. Huffnagle GB, Noverr MC. The emerging world of the fungal microbiome. Trends Microbiol. 2013:21(7):334-41. https://doi. org/10.1016/.tim.2013.04.002

47. Cox MJ, Allgaier M, Taylor B, Baek MS, Huang YJ, Daly RA, et al. Airway microbiota and pathogen abundance in age-stratified cystic fibrosis patients. PLoS One. 2010;5(6):e11044. https://doi. org/10.1371/journal.pone.0011044

48. Rudkjøbing VB, Thomsen TR, Alhede M, Kragh KN, Nielsen PH, Johansen UR, et al. The microorganisms in chronically infected endstage and non-end-stage cystic fibrosis patients. FEMS Immunol Med Microbiol. 2012;65(2):236-44. https://doi.org/10.1111/j.1574695X.2011.00925.X

49. Frayman KB, Armstrong DS, Carzino R, Ferkol TW, Grimwood K Storch GA, et al. The lower airway microbiota in early cystic fibrosis lung disease: a longitudinal analysis. Thorax. 2017;72(12):1104-1112. https://doi.org/10.1136/thoraxjn-2016-209279

50. Adami AJ, Cervantes JL. The microbiome at the pulmonary alveolar niche and its role in Mycobacterium tuberculosis infection. Tuberculosis (Edinb). 2015;95(6):651-658. https://doi.org/10.1016/j. tube.2015.07.004

51. Querido SM, Back-Brito GN, Dos Santos SS, Leão MV, KogaIto $\mathrm{CY}$, Jorge $\mathrm{AO}$. Opportunistic microorganisms in patients undergoing antibiotic therapy for pulmonary tuberculosis. Brazilian J Microbiol. 2011;42(4):1321-8. https://doi.org/10.1590/S151783822011000400012

52. Dubourg G, Lagier JC, Armougom F, Robert C, Hamad I, Brouqui $P$, et al. The gut microbiota of a patient with resistant tuberculosis is more comprehensively studied by culturomics than by metagenomics. Eur J Clin Microbiol Infect Dis. 2013;32(5):637-45. https://doi.org/10.1007/s10096-012-1787-3

53. Cui Z, Zhou Y, Li H, Zhang Y, Zhang S, Tang S, et al. Complex sputum microbial composition in patients with pulmonary tuberculosis. BMC Microbiol. 2012;12:276. https://doi.org/10.1186/1471-2180-12-276

54. Wu J, Liu W, He L, Huang F, Chen J, Cui P, et al. Sputum microbiota associated with new, recurrent and treatment failure tuberculosis. PLoS One. 2013;8(12):e83445. https://doi.org/10.1371/journal. pone. 0083445

55. Varney VA, Parnell HM, Salisbury D., Ratnatheepan S, Tayar RB. A double blind randomised placebo controlled pilot study of oral $\mathrm{CO}$ trimoxazole in advanced fibrotic lung disease. Pulm Pharmacol Ther. 2008;21(1):178-87. https://doi.org/10.1016/j.pupt.2007.02.001

56. Han ML, Zhou Y, Murray S, Tayob N, Noth I, Lama VN, et al. Lung microbiome and disease progression in idiopathic pulmonary fibrosis: an analysis of the COMET study. Lancet Respir Med. 2014;2(7):54856. https://doi.org/10.1016/S2213-2600(14)70069-4

57. Molyneaux PL, Cox MJ, Willis-Owen SA, Mallia $P$, Russell KE, Russell AM, et al. The role of bacteria in the pathogenesis and progression of idiopathic pulmonary fibrosis. Am J Respir Crit Care Med. 2014;190(8):906-13. https://doi.org/10.1164/rccm.20140305410C

58. Huang Y, Ma SF, Espindola MS, Vij R, Oldham JM, Huffnagle GB, et al. Microbes Are Associated with Host Innate Immune Response in Idiopathic Pulmonary Fibrosis. Am J Respir Crit Care Med. 2017;196(2):208-219. https://doi.org/10.1164/rccm.201607-15250C

59. Molyneaux PL, Willis Owen SAG, Cox MJ, James P, Cowman $\mathrm{S}$, Loebinger $\mathrm{M}$, et al. Host-Microbial Interactions in Idiopathic Pulmonary Fibrosis. Am J Respir Crit Care Med. 2017;195(12):16401650. https://doi.org/10.1164/rccm.201607-14080C

60. Zakharkina T, Martin-Loeches I, Matamoros S, Povoa P, Torres A, Kastelijn JB, et al. The dynamics of the pulmonary microbiome during mechanical ventilation in the intensive care unit and the association 
with occurrence of pneumonia. Thorax. 2017;72(9):803-810. https:// doi.org/10.1136/thoraxjnl-2016-209158

61. Yin $Y$, Hountras $P$, Wunderink RG. The microbiome in mechanically ventilated patients. Curr Opin Infect Dis. 2017;30(2):208-213. https:// doi.org/10.1097/QCO.0000000000000352

62. Borewicz K, Pragman AA, Kim HB, Hertz M, Wendt C, Isaacson RE. Longitudinal analysis of the lung microbiome in lung transplantation. FEMS Microbiol Lett. 2013;339(1):57-65. https://doi. org/10.1111/1574-6968.12053

63. Willner DL, Hugenholtz P, Yerkovich ST, Tan ME, Daly JN, Lachner $\mathrm{N}$, et al. Reestablishment of recipient-associated microbiota in the lung allograft is linked to reduced risk of bronchiolitis obliterans syndrome. Am J Respir Crit Care Med. 2013;187(6):640-7. https:// doi.org/10.1164/rccm.201209-16800C

64. Bernasconi E, Pattaroni C, Koutsokera A, Pison C, Kessler R, Benden $\mathrm{C}$, et al. Airway microbiota determines innate cell inflammatory or tissue remodeling profiles in lung transplantation. Am J Respir Crit Care Med. 2016:194(10):1252-1263. https://doi.org/10.1164/ rccm.201512-2424OC
65. Meyer MS, Joshipura K, Giovannucci E, Michaud DS. A review of the relationship between tooth loss, periodontal disease, and cancer Cancer Causes Control. 2008;19(9):895-907. https://doi.org/10.1007/ s10552-008-9163-4

66. Vogtmann E, Goedert JJ. Epidemiologic studies of the human microbiome and cancer. Br J Cancer. 2016;114(3):237-42. https://doi. org/10.1038/bjc.2015.465

67. Lee SH, Sung JY, Yong D, Chun J, Kim SY, Song JH, et al. Characterization of microbiome in bronchoalveolar lavage fluid of patients with lung cancer comparing with benign mass like lesions. Lung Cancer. 2016;102:89-95. https://doi.org/10.1016/1. lungcan.2016.10.016

68. Hanage WP. Microbiome science needs a healthy dose of skepticism. Nature [Internet]. 2014;512(7514):247-8. https://doi. org/10.1038/512247a

69. Dickson RP, Morris A. Macrolides, inflammation and the lung microbiome: untangling the web of causality. Thorax. 2017;72(1):1012. https://doi.org/10.1136/thoraxjnl-2016-209180 